\title{
Cultura Identitária pró-anorexia: características de um estilo de vida em uma comunidade virtual ${ }^{*}$
}

Juliana de Souza Ramos ${ }^{1}$

André de Faria Pereira Neto ${ }^{2}$

Marcos Bagrichevsky³

RAMOS, J.S.; NETO, A.F.P.; BAGRICHEVSKY, M. Pro-anorexia cultural Identity:

characteristics of a lifestyle in a virtual community. Interface - Comunic., Saude, Educ., v.15, n.37, p.447-60, abr./jun. 2011.

Anorexia nervosa is a disease listed in the International Classification of Diseases. However, young pro-anorexics believe they are adopting a "lifestyle". The aim of this paper is to analyze the "cultural identity" of these youths, investigating a Brazilian virtual community. Virtual Ethnography was used methodologically in three "units of meaning" found in this community: the tension between anorexia as a disease versus anorexia as a lifestyle; the ideal of perfection; and the meaning of belonging to the group. The results suggest that pro-anorexia identity differs from the biomedical model. It admits that the thin body serves as reference for social recognition and economic success. In this sense, the online forums allow for identity construction based on anonymity. Studies of anorexic practices in virtual communities should be encouraged because they contribute to the understanding of the adolescents' universe and collaborate with the promotion of policies and actions targeted at their health.

Keywords: Anorexia. Adolescent behavior. Webcasts. Internet.
Anorexia nervosa é uma doença inscrita na "Classificação Internacional de Doenças". Entretanto, jovens pró-anoréxicas acreditam que estejam adotando um "estilo de vida". O objetivo deste artigo é analisar a "cultura identitária" dessas jovens, investigando uma comunidade virtual brasileira. Metodologicamente, foi utilizada a Etnografia Virtual em três "núcleos de sentido" identificados na comunidade: a tensão entre anorexia como doença versus estilo de vida; as versões sobre ideal de perfeição e o significado do pertencimento ao grupo. Os resultados encontrados sugerem que a identidade pró-anorexia diverge do modelo biomédico. Ela admite que o corpo magro serve como referência de reconhecimento social e sucesso econômico. Neste sentido, os fóruns online permitem uma construção da identidade pautada no anonimato. Conclui-se que estudos sobre práticas anoréxicas em comunidades virtuais devem ser estimulados, pois contribuem para a compreensão do universo juvenil e colaboram com a promoção de políticas e ações voltadas para a saúde do adolescente.

Palavras-chave: Anorexia. Comportamento do adolescente. Webcasts. Internet.

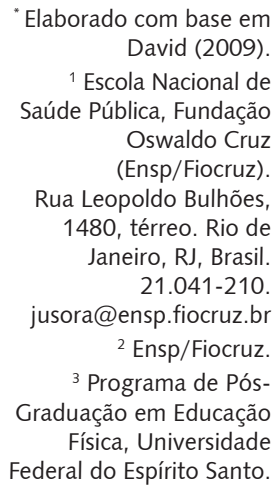

"Elaborado com base em David (2009).

1 Escola Nacional de Saúde Pública, Fundação Oswaldo Cruz (Ensp/Fiocruz).

Rua Leopoldo Bulhões, 1480, térreo. Rio de Janeiro, RJ, Brasil. 21.041-210 jusora@ensp.fiocruz.br 2 Ensp/Fiocruz.

${ }^{3}$ Programa de PósGraduação em Educação

Física, Universidade Federal do Espírito Santo. 


\section{Introdução}

A anorexia nervosa é uma doença descrita na Classificação Estatística Internacional de Doenças e Problemas Relacionados à Saúde (CID-10) como um "transtorno da alimentação, caracterizado pela perda de peso intencional, induzida e mantida pelo paciente" (OMS, 2008, p.50). A incidência desse transtorno praticamente dobrou nestes últimos vinte anos, atingindo, sobretudo, adolescentes e jovens na faixa etária de dez a 19 anos, do gênero feminino (Dunker, Philippi, 2003). Tal cenário aponta para a importância da temática para o campo da saúde pública e para as ações na área de saúde do adolescente (Brasil, 2005).

Segundo Lira (2006), o aumento da prática anoréxica entre jovens do sexo feminino faz parte de um movimento mundial, facilitado, sobretudo, na década de 1990, pelo uso da Internet. Para Brotsky e Giles (2007), até então, os indivíduos anoréxicos dificilmente discutiam seus transtornos alimentares fora dos consultórios psiquiátricos ou psicanalíticos. Atualmente, existem milhares de comunidades virtuais onde as pessoas interessadas na diminuição ou perda de apetite acompanhada por uma aversão à comida conversam sobre o tema publicamente. Elas são frequentadas por adolescentes e jovens, que consideram a anorexia um estilo de vida ${ }^{4}$ e não compartilham a ideia de que ela seja um transtorno da alimentação ou uma doença (Possas, 1989). Entre as práticas que realizam constam: os jejuns prolongados, os vômitos autoinduzidos e uso de medicamentos para emagrecer. As anoréxicas encontraram, nestes ambientes virtuais, um espaço inédito para se relacionarem e compartilharem experiências de forma segura, garantida pela ausência da identidade da participante (Gavin, Rodham, Poyer, 2008; Brotsky, Giles, 2007; Pereira, 2007; Fox et al.,2005).

Mas o que faz de uma pessoa uma anoréxica? Como sua identidade pode ser caracterizada? Dubar (1997) define a identidade como uma construção social, dinâmica e processual, que se relaciona com a história de vida de uma pessoa e que remete à dimensão do reconhecimento, do pertencimento e da identificação do indivíduo a partir de traços comuns. Essa definição é útil na análise das interações sociais mediadas pela internet, onde se encontram comunidades virtuais, de acesso público, voltadas para pessoas que têm medo excessivo de adquirir sobrepeso. Neste caso, a construção social da identidade se desenvolve por meio de negociações, que estão permeadas por sentimentos e expectativas. O significado cultural do corpo e de sua imagem social desempenha um papel determinante na construção da identidade das pessoas anoréxicas. O ponto de vista apresentado neste artigo admite que o corpo não seja visto apenas em termos biológicos. Ele é percebido como uma construção cultural, passível de interpretação e significação por diferentes sociedades, em contextos históricos distintos, como analisou Mauss (2003).

Mauss (2003) oferece uma reflexão interessante para esta questão quando analisa o significado que a pessoa atribui a seu corpo, a partir das negociações com a ordem social, os modelos vigentes e o uso que ela faz do mesmo. No caso das pró-ana, a tensão está situada entre considerar a anorexia uma doença ou um estilo de vida. Neste caso, podem ser observadas representações sobre o que é cultuado ou desejado e o que deve ser evitado ou eliminado, pois prejudica a saúde.

O objetivo deste estudo é observar as relações, processos e fenômenos expressos nas palavras das jovens que participam de uma comunidade virtual, buscando identificar o universo de significados, motivos, crenças e atitudes que as levam a crer que tenham um estilo de vida diferente, mas que não estejam doentes.

\footnotetext{
${ }^{4}$ Este estudo utiliza o conceito de 'estilo de vida' cunhado por Possas (1989). Segundo esta autora, o 'estilo de vida' se traduz através de uma determinada forma social e cultural de viver, que se expressa em condutas e comportamentos como: a prática (ou não) de esportes, da dieta e dos hábitos de consumo (ou não) de tabaco e álcool, entre outros.
} 


\section{Metodologia}

Existem diversos métodos de natureza qualitativa capazes de auxiliar o entendimento e a obtenção de informações relevantes nas comunidades virtuais. Dentre eles, chama a atenção o surgimento de uma metodologia de pesquisa no ciberespaço denominada etnografia on-line, etnografia virtual ou netnografia. Esta metodologia foi concebida para a análise de comunidades que passaram a ter como rotina o relacionamento em ambientes de comunicação eletrônica mediados por computador, no ciberespaço. A etnografia virtual guarda algumas semelhanças com a etnografia presencial. Em primeiro lugar, cabe enfatizar que ambas desenvolvem estudos de grupos sociais procurando identificar sua natureza e singularidade. A observação participante e a análise de discurso são alguns dos procedimentos adotados por ambas. Nos dois casos, a ênfase está situada no ponto de vista da comunidade que está sendo investigada. O objetivo da etnografia virtual é compreender o significado dos comportamentos e valores praticados virtualmente por uma dada comunidade. A etnografia virtual se apropria, portanto, de determinados conceitos que foram cunhados para o estudo das culturas no território real ou concreto. Entretanto, os conceitos da etnografia tradicional não podem ser absorvidos de forma automática. É necessário que sejam realizadas adaptações e análises das possibilidades e dos limites de tal adaptação para a pesquisa efetuada na web. A etnografia virtual visa decodificar a experiência humana presente nas comunidades virtuais com o intuito de conhecer os sentidos, significados e lógicas subjacentes aos comportamentos e valores expostos.

Dois autores parecem despontar neste campo: Christine Hine (2005) e Robert Kozinets (2010). Este último enfatiza em sua análise que a netnografia:

[...] tem sido desenvolvida na área do marketing e na pesquisa sobre perfil do consumidor - um campo interdisciplinar aplicado que está aberto com o desenvolvimento e a adoção de novas técnicas. (Kozinets, 2010, p.2)

Sua ênfase está situada na análise do comportamento e desejos dos consumidores em relação a produtos e marcas em um ambiente mediado pela tecnologia.

Hine (2004, p.13), por outro lado, afirma que:

[...] Em sua forma básica, a etnografia consiste na inserção de um investigador no mundo que estuda por um tempo determinado visando observar as relações, atividades e significados que se forjam entre aqueles que participam dos processos sociais deste mundo. [...] O etnógrafo se estabelece em um mundo intermediário, sendo simultaneamente um estranho e um nativo. Ele deve conhecer a cultura que estuda para compreender seu funcionamento, sem deixar de manter a distância necessária para poder dar conta dela.

O ofício do etnógrafo virtual consiste na observação, descrição e participação do/no ambiente pesquisado (Braga, 2006). Esta observação pode ser escondida.

É essa participação (mesmo que invisível) no grupo que irá viabilizar a apreensão de aspectos daquela cultura possibilitando a elaboração posterior de uma descrição densa, que demanda uma compreensão detalhada dos significados compartilhados por seus membros e da rede de significação em questão. (Braga, 2006, p.5)

O procedimento etnográfico virtual adotado neste trabalho foi a "observação passiva". Este artigo segue o método etnográfico adotado por Gavin, Rodham e Poyer (2008), que permite ao pesquisador observar a Comunidade Virtual sem se identificar ou interagir com seus membros. Foi realizada, 
portanto, uma observação denominada lurking ${ }^{5}$, um tipo de participação especial, onde a observação é a fonte de análise dos comportamentos e valores (Braga, 2006). Seguindo esta modalidade de observação, o etnógrafo não interfere no processo, preservando a troca de mensagens entre os integrantes das comunidades virtuais.

Durante a realização da pesquisa que se transformou neste artigo, foi selecionada uma comunidade virtual pró-anorexia da plataforma orkut do Brasil. Esta comunidade foi escolhida, dentre outras existentes, pelo fato de ser aquela que tinha o maior número de pessoas inscritas no momento da observação (1.616 participantes).

As observações foram realizadas de janeiro a março de 2009. Não foi necessário obter o consentimento informado dos usuários desta comunidade virtual, tendo em vista que ela é de domínio público, e que será preservado o anonimato das participantes.

A comunidade virtual observada denomina-se "A perfeição é 1 esforço de 24 h". Ela foi acessada através das palavras-chaves "perfeição/esforço" e "anorexic". Estes são alguns sinais que sugerem que suas frequentadoras busquem práticas visando à diminuição ou perda de apetite. Quando foi observada, esta comunidade estava subdividida em três segmentos: Os fóruns onde os membros debatem questões relacionadas com o corpo, dietas e práticas alimentares; as enquetes - onde qualquer participante pode fazer uma pergunta sobre qualquer assunto, que é respondida pelos participantes e apresentada de forma estatística, e os perfis - onde os participantes se apresentam e colocam suas fotos.

Quando a observação foi realizada, esta comunidade possuía um total de 34 fóruns. Para o presente estudo foram escolhidos apenas seis fóruns, totalizando 76 participantes, sendo $99 \%$ do sexo feminino. O critério utilizado para selecionar esses fóruns foi o mesmo utilizado por Gavin, Rodham e Poyer (2008): o maior número de acessos no período pesquisado. Os títulos dos fóruns selecionados englobaram temas relacionados ao tema deste artigo, a saber: "Como faço para perder coxa?"; "O que é ser perfeita para vocês?"; "O que acham?"; "Não sei mais como responder"; "Meninas, qual a altura, o peso e a idade de vocês?" e "Vinagre e limão emagrecem ou é lenda?". Apesar de não se autodenominarem anoréxicas, os títulos dos fóruns sugerem que as participantes têm certa obsessão por perderem peso e adquirirem um corpo perfeito - características consideradas próprias das anoréxicas. Na verdade, não se trata de uma comunidade virtual que reúne jovens que procuram a magreza. Como será analisado a seguir, elas se autoajudam e desenvolvem uma série de comportamentos que se destinam a atingir o corpo considerado ideal.

A unidade de análise apresentada neste artigo foram os fóruns onde são travados os diálogos entre suas integrantes neste ambiente virtual. Para tanto, foi realizada uma leitura e seleção dos trechos que melhor representam a visão das participantes em relação às praticas anoréxicas associadas ao estilo de vida, e não a uma prática nociva à saúde.

Um dos grandes desafios intelectuais contemporâneos está associado à discussão da identidade cultural em tempos de globalização. Neste sentido, a obra de Hall (1999) tem se transformado em obra de referência. A questão parece residir na dificuldade de se pensar a construção da identidade cultural em relação à produção de uma alteridade em um mundo globalizado. Abandonando a concepção identitária essencialista, Hall (1999) admite que o sujeito na pósmodenidade (re)produz, representa e (re)significa sua identidade cultural. Agier
${ }^{5}$ Esta expressão significa, em português, "ficar à espreita". 
(2001) complementa esta visão afirmando que o etnógrafo pós-moderno encontra-se diante de "culturas identitárias" em fabricação, e não perante identidades culturais totalmente prontas, as quais ele teria apenas de descrever e inventariar. No seu entender: a emergência das "culturas identitárias" em um contexto de globalização é acelerada pelas situações locais (Agier, 2001, p.7). Estes parecem ser alguns marcos conceituais úteis para o desenvolvimento deste trabalho.

Os trechos selecionados na análise que se segue revelam a tensão existente entre anorexia como doença versus anorexia como estilo de vida. Este artigo apresenta a "cultura identitária" (Agier, 2001) pró-ana como algo que se constrói em torno desta estrutura dual. A partir desta oposição, elabora-se um conjunto de expectativas e procedimentos sobre o corpo perfeito e o sentimento de pertencimento ao grupo.

Os trechos selecionados foram submetidos a uma análise temática, buscando-se encontrar os principais núcleos de sentido (Minayo, 2008). Eles reúnem algumas ideias centrais dos atores sociais e revelam momentos-chave de sua existência. Trata-se, portanto, de uma metodologia de caráter qualitativo. Esta investigação não operacionalizou variáveis quantitativas. Ela não se preocupou em mensurar a frequência de certas palavras ou expressões. Sua atenção não esteve voltada para a identificação da presença ou ausência de uma determinada característica ou mensagem. Ela procurou ultrapassar o alcance meramente descritivo das técnicas quantitativas para buscar atingir interpretações mais profundas, com base na inferência.

A identificação e análise dos "núcleos de sentido" foram úteis para este estudo, pois contribuíram para a compreensão do que está por trás dos conteúdos explicitados, permitindo ir além das aparências. As etapas deste trabalho foram as seguintes: identificação das ideias centrais (núcleos de sentido) das intervenções dos usuários; análise destas ideias com base na produção bibliográfica identificada sobre o tema, e determinação de eixos temáticos e discussão das categorias encontradas.

\section{Discussão e resultados}

Foram identificados três núcleos de sentido (Minayo, 2008). Um refere-se à tensão existente entre o entendimento da anorexia como doença em oposição à ideia da anorexia como estilo de vida, que implica dedicação e sacrifício. Outro relaciona-se com os objetivos que elas esperam alcançar com este estilo de vida: felicidade e realização profissional. O terceiro núcleo reporta-se aos sentidos atribuídos ao pertencimento a este grupo virtual pró-anorexia, relacionado com a segurança e liberdade que o anonimato oferece. Combinados, estes três "núcleos de sentido" participam do processo de construção da "cultura identitária" (Agier, 2001) pró-ana presente nesta comunidade virtual.

\section{Estilo de vida}

O primeiro núcleo de sentido (Minayo, 2008), a reflexão sobre estilo de vida, parece ocupar um lugar central. Aqui a ideia de emagrecer associada à doença é condenada, enquanto a visão do emagrecimento como uma necessidade estética aparece como uma prática saudável e desejada. Uma participante afirmou:

"sou contra emagrecer até ficar com cara e corpo de doente, mas pra ficar na medida certa eu sou a favor!!". (K.)

"Medida certa"? O que esta participante pretende dizer com a expressão?

Para melhor analisar o perfil das participantes dessas comunidades virtuais, foi feito um levantamento contendo a altura e o peso para se obter o índice de massa corporal (IMC) e a classificação do estado nutricional das participantes. Por meio do cálculo do IMC, foi constatado que cerca de $60 \%$ encontravam-se com o peso normal, $20 \%$ com sobrepeso e $20 \%$ com baixo peso. A participante $\mathrm{K}$, mencionada acima, estava com peso normal, segundo o IMC. 
Seguindo a mesma linha de argumentação, Pereira (2007), também, calculou o IMC das participantes de vinte blogs brasileiros e verificou que $60 \%$ delas tinham IMC na faixa de normalidade e que apenas $15 \%$ estavam na faixa de baixo peso e $20 \%$ na faixa de sobrepeso.

"Medida certa" significa, então, atingir um peso inferior ao considerado normal pelo IMC.

Para as participantes, atingir esta meta não é suficiente. É necessário ainda ter um "corpo perfeito". E o que significaria isso? Dois depoimentos podem servir de exemplo:

\footnotetext{
"Ser perfeita é ter quadril, coxas e braços finos, barriga chapada e ter os ossos do quadril aparecendo". (Ju *no name*)

"Ser perfeita é apertar-se com uma pinça e não com um alicate pra conseguir achar uma gordurinha". (Luana blogs)
}

Este estudo verificou que muitas participantes relataram que "ser perfeita" é ter um corpo magro, com pernas, cintura e braços finos. Para elas, não basta "ficar na medida". É necessário, também, ter determinadas partes do corpo magras.

A situação oposta é considerada abominável. Em um dos fóruns, foi identificado o seguinte depoimento:

"Ridiculooo...ser gordaa eh ridiculooo!!!!!! Vestir uma calça jeans e as banhas pularem para fora da roupa.....Isso eh ridiculooo!". (K.)

Lira (2006) chegou a conclusões semelhantes ao estudar os diários virtuais de pró-anoréxicas. A autora verificou que os ossos no corpo de uma anoréxica simbolizam aquela parte do corpo que não está sujeita aos estereótipos de beleza ou feiúra. Para Lira (2006), o ideal de perfeição é atingido pelas 'pró-anas' quando é possível emagrecer a ponto de ter a visibilidade dos ossos.

Damico (2004) analisou os discursos de jovens escolares sobre as estratégias utilizadas nos dias de hoje para cuidar do corpo. O autor constatou que elas possuem uma imagem corporal ideal semelhante àquela das frequentadoras da comunidade virtual analisada neste trabalho. Ambas se preocupam mais com as partes mais "macias ou protuberantes do corpo", especialmente o excesso de gordura na barriga, nas nádegas e nos quadris (Damico, 2004, p.74). Elas desejam ter um corpo magro e livre de gordura. Elas querem que os ossos, em algumas partes do corpo, apareçam e sejam vistos. O autor observou, ainda, que as jovens "são educadas para exibir seu corpo de acordo com a moda, usando mini-blusas, calças e mini-saias de cintura baixa, biquínis fio dental e blusas de alcinhas" (Damico, 2004, p.12). Para o autor, essas vestimentas podem se tornar constrangedoras quando o corpo não está adequadamente preparado para exibi-las. Isso pode ocorrer quando barriga é perceptível ou perna está mal definida, ou, como disse a participante acima, as "banhas pularem para fora da roupa".

Os resultados obtidos pelos autores supracitados coincidem com os depoimentos observados neste estudo. Por esta razão, admite-se que estas participantes estejam adotando práticas que possam ser denominadas anoréxicas, apesar de as participantes não considerarem o mesmo.

Ao se analisarem as explicações sobre o corpo, verificou-se que elas desejam ter um corpo magro, sem gordura, especialmente, nas partes consideradas mais volumosas, como quadril, coxas, braços e barriga. Elas desejam ter os ossos expostos e se sentem frustradas quando o corpo está fora dos padrões idealizados. As participantes desses fóruns vivem em constante busca pela magreza e rejeitam qualquer sinal de gordura em seus corpos.

Emagrecer e atingir a "medida certa" e o "corpo perfeito" é uma prática que impõe sacrifícios. O depoimento de Fanna Voltando parece exemplificar este traço distintivo desta cultura identitária (Agier, 2001) anoréxica. 


\begin{abstract}
"de tempos, em tempos, sempre surge aqueles momentos em que ficamos determinadas a conseguir, sempre pensamos, não agora vai, vou emagrecer, tudo bem, compramos laxantes, vemos milhões de fotos de thinspos, e insistimos em vomitar, mas aí vem a fraqueza, e do nada começamos a comer tudo de novo, ou quando pior mais ainda [...] se vc quer emagrecer, feche a boca, e se concentre, você pode conseguir, é um esforço diário, que no fim vale a pena, vc só tem ganhar, seja onde for, na auto-estima, nas amigas e muito mais com os gatos, se você parar para pensar na recompensa, vê que td sacrifício vale a pena! e ninguém vira anna do dia para noite, ou da noite para o dia, isso são longos e longos meses, ou pq não anos de vida". (Fanna Voltando)
\end{abstract}

Práticas tipicamente anoréxicas, como comprar laxantes, insistir em vomitar, são propostas neste depoimento. A dor, fruto do esforço físico, tem uma conotação especial neste contexto. Torri et al. (2007) realizaram um estudo cujo objetivo foi estudar "as práticas de modelação corporal entendidas como intervenções tecnológicas sobre o corpo, políticas de consumo e juventude" (Torri et al., 2007, p.261). Nesse estudo, os autores também observaram que os indivíduos frequentadores de academias "naturalizam" a dor e o sofrimento corporal. A dor para esses indivíduos possui, também, um "caráter legitimador", ou seja, o indivíduo deve pagar o preço para obter o corpo perfeito, independente de sentir dor ou não (Torri et al., 2007, p.266, 227). Os autores demonstraram, ainda, que os professores utilizavam estratégias para seus alunos suportarem a dor, como frases de incentivo, "vamos lá, vocês conseguem!", e até ameaças, como "quem não for até o final vai se encher de celulite" (Torri et al., 2007, p.268). Na comunidade virtual investigada, as estratégias para suportar a dor partem das próprias participantes.

“Coma muito pouco! pouco mesmo, mais continue nessa luta que vc consegue viu? beijos!". (Karol)

O trecho acima demonstra que, para participar desta cultura identitária (Agier, 2001), é necessário muito esforço e sacrifício, pois só assim as metas podem ser alcançadas. A participante declarou que todas as pessoas que desejam ter corpos magros necessitam de esforço, sacrifício, autocontrole e disciplina. O estilo de vida de uma anoréxica segue, portanto, um modelo de beleza vigente e obedece a um rígido sacrifício. Este primeiro núcleo de sentido participa do processo de construção da cultura identitária (Agier, 2001) que transforma uma prática considerada doentia em algo saudável, apesar de exigir sacrifícios.

\title{
Magro, rico e feliz
}

O segundo núcleo de sentidos (Minayo, 2008) reúne as expressões e trechos selecionados nos fóruns que dizem respeito às expectativas das participantes para alcançarem o padrão de um corpo magro. Neste caso, o sacrifício não é pensado apenas para atender a um padrão estético. O ideal de perfeição física nesta cultura identitária (Agier, 2001) também está associado a um futuro feliz e financeiramente próspero:

“perfeição pra mim é ser magérrima, usar a roupa q eu quiser e ser paquerada pelos garotos... ser invejada pelas meninas, e ser linda como as modelos!". (C.)

“Ser magérrima e poder vestir o q quiser..... ou não vestir nada rsss causar inveja e admiração ter um empregão. e ser bem-sucedida ter uma ótima formação: facul, pós e etc ter um gato bem lindo q me ama".

As explicações sobre ser perfeita passam a estar relacionadas, também, com a expectativa de ser desejada e admirada. Além disso, participantes desses fóruns relacionam o padrão magro de beleza com um cidadão bem-sucedido social e economicamente. 
Esses trechos revelam, ainda, que a busca pelo corpo magro sofre forte influência do que é divulgado na mídia (Añaña et al., 2008). As modelos se transformam no parâmetro do que se deseja ser e ter em matéria de corpo magro e de processo de reconhecimento e integração social.

Brandini (2007) demonstrou que a atual cultura do corpo é retroalimentada pelo universo da moda, que promove práticas, atitudes, técnicas, tecnologias e mercados que podem ser vistos como ideais. Para tanto, são difundidos modelos consensualmente aceitos que devem ser seguidos. Na década de 1950/60, por exemplo, Marilyn Monroe era considerada a mulher mais sexy. Ela usava manequim 42, com cintura de 72/74 centímetros e quadril 98 . Hoje, no início do século XXI, o tipo de corpo feminino ideal possui manequim 36, cintura de 50/60 centímetros e quadril 80. Para Alvarenga (2004), o conceito atual de beleza feminina não é o mesmo da década de 1950. No seu entender, a valorização do corpo magro suplantou o modelo do corpo cheio de curvas. Para Goldenberg (2005), o culto ao corpo magro tornou-se uma verdadeira obsessão no Brasil, sobretudo, a partir do final do século XX e início do século XXI. Para ela, existe, atualmente, uma geração que cresceu tentando imitar o corpo de modelos e cantoras famosas, como Kate Moss ou a Beyoncé. Para Reis e Silveira Júnior (2008), a inspiração por celebridades é um traço marcante de fóruns virtuais pró-anorexia. Para as autoras, as participantes desses fóruns recebem influência das atrizes e modelos famosas, que expõem, através da mídia, seus corpos considerados perfeitos pela sociedade ocidental. Além disso, elas servem de estímulo para as 'pró-anas', pois têm corpos bem torneados e magros e são bem-sucedidas financeira e socialmente. Elas servem como thinspiration. Uma participante declarou: "Ser perfeita é ter o corpo de Kate Moss" (Satella).

Niemeyer e Kruse (2008) estudaram a influência da mídia na construção do corpo magro ao analisarem os discursos da revista Capricho. Eles constataram que esta revista divulga mensagens contraditórias, pois condena a anorexia como doença e, ao mesmo tempo, incentiva as adolescentes a terem atitudes anoréxicas. Além disso, a revista valoriza o corpo magro como sendo o corpo perfeito e prescreve medidas para corrigir aqueles que estão imperfeitos. Medina (2007), em seu estudo sobre blogs pró-ana, constatou, também, que as participantes desses espaços virtuais não expõem suas fotos em suas páginas, pois demonstram uma "fascinação pela imagem do outro" (Medina, 2007, p.48). Consequentemente, negam sua própria imagem, considerando-a imperfeita e fora do padrão magro de beleza.

Para Goldenberg (2005), o culto obsessivo ao corpo, na sociedade contemporânea, aprisiona as mulheres, levando-as a viverem em busca do padrão magro de beleza. A autora demonstrou que as mulheres dos anos oitenta promoveram uma libertação de seus corpos com relação à sexualidade $e$ as roupas que deveriam utilizar. Atualmente, ocorre o contrário. A autora verifica que está ocorrendo uma padronização dos corpos e um processo em que as mulheres estão preocupadas em se manterem jovens e magras. Para atingirem esta finalidade, utilizam vários recursos, como dietas, ginástica e cirurgias plásticas.

Desse modo, corroborando com as autoras acima, este estudo admite que o ideal de perfeição para essas participantes de fóruns analisados vai muito além de ter apenas um corpo magro. Elas desejam também, mesmo que subjetivamente, possuir um status perante a sociedade, uma vez que ter o corpo magro, no entender dessas participantes, está relacionado com: ser bem-sucedida, desejada, invejada, ter dinheiro, fama, bom emprego e ser amada. Assim, todo aquele esforço e sacrifício seriam, de alguma forma, recompensados.

Damico e Meyer (2007) entendem que a gordura e a flacidez são avaliadas, pelos indivíduos que cultuam o corpo magro, como sinais de "indisciplina e desleixo" (Damico, Meyer, 2007, p.87). Para Sibilia (2004), os indivíduos com sobrepeso e obesos são considerados, pela sociedade contemporânea, maus gestores de si. Por esta razão, são considerados sujeitos sem autocontrole e moralmente fracos. Santos (2008), seguindo a mesma linha de argumentação, demonstrou que a imagem de um corpo magro está relacionada com indivíduos de sucesso, que conseguem ter um maior controle sobre seu comportamento alimentar. Por outro lado, o indivíduo gordo significa um fracassado, preguiçoso e desleixado, pois demonstra ser incapaz de se autocontrolar. Miskolci (2006) concorda com este ponto de vista. Para este autor, um corpo gordo não caracteriza apenas um sujeito "feio ou disforme", mas, também, gera um pensamento "autodestrutivo" que busca, muitas vezes, uma adequação a qualquer custo ao padrão magro (Miskolci, 2006, p.685). 
O segundo núcleo de sentido participa do processo de construção da cultura identitária (Agier, 2001), pois associa esta prática ao sucesso pessoal e profissional, excluindo os gordos, que seriam, por esta condição, fadados ao fracasso.

\section{Estar em comunidade}

O terceiro núcleo de sentido (Minayo, 2008) enfatiza a importância da existência das comunidades virtuais. Lá a identidade condenável pela medicina e pela sociedade se mantém imune e as praticantes conseguem apoiar-se reciprocamente. Por esta razão, todas as praticantes são honestas acerca de seus comportamentos alimentares. Esta honestidade, entretanto, não pode ser transmitida para o mundo real, devido às possíveis retaliações que receberiam da família e dos colegas. No mundo virtual, elas procuram encontrar a melhor maneira de reagir ao mundo real, quando este as indaga.

Este foi o caso de uma participante que declarou ao namorado que desejava fazer uma lipoaspiração para retirar "as gorduras nojentas de seu corpo". Ela não obteve apoio dele. Quando ela contou a reação do namorado, na comunidade virtual, às demais participantes, disseram que ela não deveria ter falado para seu namorado sobre a lipoaspiração. Elas ainda deram sugestões sobre como esconder de namorado sua identidade. Brida declarou a seguinte frase:

"Mostra pelo menos na frente dele q vc tah comendo... tipo deixa pra comer com ele, quando vc tiver sozinha não come... se cuida." (Brida)

Kally seguiu a mesma linha de argumentação dizendo:

"Evite ficar conversando sobre planos de comida, lipo perto dele, aí que ele vai ficar bravo! Força aí que vc consegue linda." (Kally)

Estes dois relatos revelam as dificuldades encontradas, pelas participantes desta comunidade virtual, para esconder da família e amigos mais próximos os comportamentos considerados doentios pela sociedade e pela medicina. Como o estilo de vida transcende o mundo virtual, as atitudes e os comportamentos no mundo real fazem com que as pessoas que estão mais próximas comecem a desconfiar do emagrecimento de tais participantes. Os comportamentos pró-anoréxicos e o emagrecimento de uma filha podem ser percebidos por seus pais na convivência diária no lar. Desse modo, mesmo não conhecendo a identidade virtual de seus filhos, os pais, amigos e parentes podem desconfiar e até descobrir o estilo de vida pró-anoréxico de seus filhos, ao encontrarem purgantes nas gavetas, vestígios de vômito no banheiro ou, até mesmo, constatarem uma perda súbita de peso.

Além disso, as participantes apoiam umas às outras e divulgam as práticas anoréxicas bemsucedidas. Elas também podem apresentar dúvidas que são, muitas vezes, sanadas por outra participante. Um exemplo pode ser oferecido neste sentido:

“Vinagre e limão emagrece ou é lenda? Minha vó me falou que quando era jovem ela chupava 1 limão por dia e começou a perder peso, será que é verdade?" (V.)

“[...] na verdade, é verdade, mas só sobre o limão. Ele é um agente purificador no corpo e quebra as células de gordura, tanto que existe um dieta do limão, pode pesquisar. ahhh, até a Beyoncé fez uma dieta com bastante limão, o nome da dieta é master cleanse." (B.)

$\mathrm{Na}$ verdade, muitas jovens que procuram ser magras são parecidas com as que se reúnem nesta comunidade. A diferença é que as jovens que frequentam a comunidade analisada neste trabalho se expõem, compartilham dúvidas e participam do processo de construção da cultura identitária (Agier, 2001) anoréxica. Não se trata, portanto de uma comunidade que se limita a cultuar os padrões de beleza contemporâneos. Nos diálogos travados entre elas na comunidade virtual investigada, são 
utilizadas expressões que denotam, também, práticas da mesma ordem, como miar (vomitar), Ana (anorexia), LF (light food) e NF (no food).

As comunidades virtuais adquirem, portanto, um significado singular. As praticantes se refugiam nestes ambientes porque fora deles suas ideias e práticas são criticadas e até condenadas. As comunidades virtuais representam, neste caso, um refúgio. Para Damico e Meyer (2005), elas são um ambiente onde se podem dividir as práticas e os sentimentos na busca pela magreza. Fox et al. (2008) demonstraram que os sites pró-anorexia têm o objetivo de gerenciar as práticas anoréxicas, e, por isso, proporcionam um "espaço livre de julgamento". Neles esses indivíduos podem se sentir seguros, obter apoio e compartilhar experiências.

O ponto de vista de Recuero (2005) se assemelha ao de Fox et al. (2008). Ele demonstrou que a interação entre os participantes destas comunidades é "mútua e cooperativa" e visa fortalecer os laços de solidariedade e oferecer suporte ao grupo. Para esta autora, os laços sociais podem ser "fortes ou fracos". Os laços fortes são aqueles que se caracterizam pela intimidade, pela proximidade e pela intencionalidade em criar e manter uma conexão entre duas pessoas. Os laços fracos, por outro lado, caracterizam-se por relações esparsas, que não traduzem proximidade e intimidade.

Os fóruns on line são, portanto, espaços de sociabilidade, que servem para manter o segredo e, também, para apoiar e compreender uns aos outros, preservando a cultura identitária (Agier, 2001) construída através da interação das partes. As usuárias aceitam os pensamentos e comportamentos anoréxicos umas das outras, permitindo que todas sejam sinceras acerca de suas práticas, valores e comportamentos. Nos fóruns virtuais, elas podem trocar experiências entre si. Essa troca fortalece 0 sentindo de pertencimento ao grupo e integra sua cultura identitária (Agier, 2001).

A sinceridade, entretanto, não pode ser compartilhada e nem revelada para o mundo real, devido às possíveis consequências. A sinceridade entre as integrantes e a segurança na preservação desta prática está presente nos significados compartilhados no material analisado. Esta questão está intimamente associada com o debate sobre a construção da cultura identitária (Agier, 2001) anoréxica. Nesse processo de construção, é essencial que haja uma identificação entre os pares por meio de sinais de distinção e semelhança que vão demarcar os traços identitários de determinados grupos em relação a outros. As participantes desses fóruns constroem uma cultura identitária valorizando o corpo magro, sem vestígio de gordura, a prática de dietas restritivas e as thinspirations. Dias (2003) ressaltou que muitas pró-anoréxicas, contrariando o modelo biomédico, consideram que anorexia seja um estilo de vida. As comunidades virtuais, neste sentido, são ambientes onde elas podem se refugiar. Além disso, essas jovens procuram uma maneira criativa de compartilharem seus pensamentos, práticas e comportamentos e fugirem do julgamento recebido no mundo real. O anonimato da internet é, também, uma questão que contribui para a construção e cultura identitária pró-ana.

Para Baldanza (2006), o anonimato introduz alguns aspectos positivos no processo de interação e sociabilidade na internet. Ele facilita, por exemplo, a comunicação virtual, pois não impõe os "bloqueios sociais ou preconceitos" inerentes, muitas vezes, à identidade real (Baldanza, 2006, p.6). A possibilidade de serem criadas identidades virtuais permite que o relacionamento seja feito "sem censura, sem compromisso e sem mobilidade territorial" (Baldanza, 2006, p.6). Verifica-se, ainda, que as participantes destes fóruns podem interagir e se relacionar livremente, independente da posição social, econômica, cor e bairro em que moram.

Seguindo a mesma linha de argumentação, Tierney (2006) demonstrou, em seu estudo, que os sites pró-anorexia geram um ambiente de segurança e confiança, onde os indivíduos que compartilham das mesmas crenças podem se relacionar livremente e não ficam mais isolados dentro de suas casas. Gavin, Rodham e Poyer (2008) corroboraram com os autores acima, pois observaram que, com o desenvolvimento dos fóruns de discussão online, os indivíduos com anorexia sofrem menos de isolamento e solidão, pois podem compartilhar seus sentimentos com outros indivíduos que possuem o mesmo estilo de vida. Os autores constataram, ainda, que: 
muitos usuários ainda se sentem incapazes de compartilhar a identidade pró-ana com aqueles que mais importam para eles. Isso indica que eles estão plenamente conscientes da controvérsia que rodeia a escolha de seus comportamentos e que eles acreditam que não serão aceitos por seus entes queridos no mundo real. (Gavin, Rodham, Poyer, 2008, p.330)

Recuero (2005) analisou a construção de identidades nas comunidades virtuais pró-anorexia. A autora verificou que os indivíduos nas comunidades visam, antes de tudo, se identificarem integrantes do grupo pró-anorexia. Isto ocorre porque, no momento que são reconhecidos como indivíduos pertencentes ao mesmo grupo social, estes indivíduos têm acesso a todo conteúdo disponibilizado pelas comunidades com as quais se identificam e são identificados. Para a autora, os anoréxicos buscam uma construção identitária nas comunidades virtuais para obterem aceitação social. Este autor verificou, ainda, que esses indivíduos estabelecem laços de amizades virtuais fortes. Os amigos virtuais são aquelas pessoas que compartilham o mesmo problema e dividem as mesmas angústias, apesar de não se conhecerem pessoalmente.

Seguindo a mesma linha de argumentação, Medina (2007) estudou os blogs e comunidades próana e pró-mia, que defendem a prática da anorexia e bulimia como estilo de vida. Para esta autora, os blogs e as comunidades são espaços onde os indivíduos confessam seus segredos e expõem sua identidade pró-ana. Além disso, esses blogs e comunidades permitem que elas se sintam pertencentes a um grupo social, pois nesses ambientes não existe julgamento e nem preconceito com relação às práticas e os comportamentos anoréxicos.

\section{Conclusão}

Ao se estudar a construção da cultura identitária (Agier, 2001) de jovens participantes de fóruns públicos pró-anorexia, pode ser constatado que, em suas falas, existe uma tensão de significados e sentidos. Elas buscam justificar o estilo de vida pró-anoréxico tentando afirmar seu lado saudável, e não doentio. As pró-anoréxicas buscam gerenciar seus próprios corpos visando atingir o ideal de magreza preestabelecido por elas mesmas e, muitas vezes, imposto pela sociedade. Essas metas têm como objetivo deixar a estrutura óssea em evidência sem resquícios de gordura.

Outra questão observada foi que o padrão de beleza magro remete a um sujeito bem-sucedido. As participantes idealizam e buscam o corpo magro que está associado com as projeções para uma vida bem-sucedida no futuro. No entanto, não pode ser esquecido que essas adolescentes estão numa fase de construção de sua própria identidade e existência pública, ou seja, ainda não atingiram a vida adulta. Por isso, há a necessidade de maiores estudos nesse campo, uma vez que a saúde dessas adolescentes e jovens é uma questão de saúde pública.

A última questão observada neste artigo foi o pertencimento ao grupo pró-anorexia, que permite a construção de uma cultura identitária (Agier, 2001), por meio do anonimato possibilitado pela internet. As participantes desses fóruns se identificam com o grupo, e, consequentemente, revelam e vivem sua identidade pró-ana com mais liberdade e de forma plena, realizando e compartilhando todos os valores e crenças de uma pró-anoréxica. No entanto, foi possível constatar que os comportamentos e as atitudes pró-anoréxicas podem ser percebidos pelos indivíduos que convivem diariamente com as integrantes desses fóruns. Elas não conseguem esconder totalmente suas atitudes e comportamentos, que podem ser notados quando rejeitam a alimentação constantemente, realizam exercício físico excessivamente, provocam vômitos ou utilizam remédios para emagrecer.

Os fóruns virtuais são ambientes onde suas participantes podem expor o estilo de vida próanoréxico sem julgamentos e preconceitos. Além disso, elas podem trocar experiências entre si e fortalecer os laços de amizade entre elas, pois dentro desse espaço virtual elas possuem proteção, reconhecimento e reciprocidade. Desse modo, a internet se tornou um importante veículo de expressão para aqueles que vivenciam a pró-anorexia em suas vidas. Ela possibilitou o encontro de pessoas que não seria possível no mundo real. Este trabalho permitiu analisar as práticas anoréxicas fora dos parâmetros médicos. 
Este artigo utilizou o procedimento metodológico da "observação passiva", desenvolvido por Gavin, Rodham e Poyer (2008). Neste sentido, ele se inscreve no debate travado pela literatura internacional a respeito do tema, trazendo como contribuição a perspectiva de um caso brasileiro. A produção nacional sobre o tema ainda é bastante incipiente. Para se ter uma ideia do quadro atual, basta mencionar que, entre os 56 títulos sobre anorexia presentes na base bibliográfica do scielo, nenhum avaliava o papel das comunidades virtuais. Da mesma forma, dos cento e noventa títulos encontrados com o indexador internet, nenhum aborda as comunidades virtuais anoréxicas. Assim, este artigo apresenta uma contribuição em relação à literatura internacional e nacional a respeito do tema.

Este artigo pretende encorajar outros pesquisadores a desenvolverem estudos sobre práticas anoréxicas em comunidades virtuais. Eles contribuem para a melhor compreensão do universo juvenil e podem colaborar com a promoção de políticas e ações voltadas para a saúde do adolescente e do jovem.

\section{Colaboradores}

Os autores trabalharam juntos em todas as etapas de produção do manuscrito.

\section{Referências}

AGIER, M. Distúrbios identitários em tempos de globalização. Mana, v.7, n.2, p.7-33, 2001.

ALVARENGA, M. A mudança na alimentação e no corpo ao longo do tempo. In: PHILIPPI, S.T.; ALVARENGA, M. (Orgs.). Transtornos alimentares: uma visão nutricional. São Paulo: Manole, 2004. p.1-20.

AÑAÑA, E.S. et al. As comunidades virtuais e a segmentação de mercado: uma abordagem exploratória, utilizando redes neurais e dados da comunidade virtual Orkut. Rev. Adm. Contemp., v.12, n.esp., p.41-63, 2008.

BALDANZA, R.F. A comunicação no ciberespaço: reflexões sobre a relação do corpo na interação e sociabilidade em espaço virtual. In: ENCONTRO DOS NÚCLEOS DE PESQUISA DA INTERCOM, 6., 2006, Rio de Janeiro. Anais... Rio de Janeiro: Intercom - Sociedade Brasileira de Estudos Interdisciplinares da Comunicação, 2006. p.1-15.

BRAGA, A. Técnica etnográfica aplicada à comunicação online: uma discussão metodológica. UNIrevista, v.1, n.3, p.1-11, 2006.

BRANDINI, V. Bela de morrer, chic de doer, do corpo fabricado pela moda: o corpo como comunicação, cultura e consumo na moderna urbe. Contemporânea, v.5, n.1, p.1-28, 2007.

BRASIL. Ministério da Saúde. Marco legal: saúde, um direito de adolescentes. Brasília: Ministério da Saúde, 2005.

BROTSKY, S.R.; GILES, D. Inside the "Pro-ana" community: a covert online participant observation. Eat. Disord., v.15, p.93-109, 2007.

DAMICO, J.G.S. Quantas calorias eu preciso gastar para emagrecer com saúde? Como mulheres jovens aprendem estratégias para cuidar do corpo. 2004. Dissertação (Mestrado) - Faculdade de Educação, Universidade Federal do Rio Grande do Sul, Porto Alegre. 2004.

DAMICO, J.G.S.; MEYER, D.E. Deixar de comer e/ou fazer exercício? Juventude, cuidados corporais e distúrbios alimentares na perspectiva de gênero. In: BAGRICHEVSKY, M. et al. (Orgs.). A saúde em debate na educação física. 1 ed. Blumenau: Editus/Universidade Estadual de Santa Catarina, 2007. v.3. p.77-104. 
DAVID, J.S.R. Anorexia em comunidades virtuais: práticas e visões culturais do corpo. 2009. Dissertação (Mestrado) - Escola Nacional de Saúde Pública Sergio Arouca, Fundação Oswaldo Cruz, Rio de Janeiro. 2009.

DIAS, K. The ana sanctuary: women's pro-anorexia narratives in cyberspace. Int. J. Women Stud., v.4, n.2, p.1-31, 2003.

DUBAR, C. A socialização-construção das identidades sociais e profissionais. Porto: Ed. Porto, 1997.

DUNKER, K.L.L.; PHILIPPI, S.T. Hábitos e comportamentos alimentares de adolescentes com sintomas de anorexia nervosa. Rev. Nutr., v.16, n.1, p.51-60, 2003.

FOX, N.; WARD, K.; O'ROURKE, A. Pro-anorexia, weight-loss drugs and the internet: an "anti-recovery" explanatory model of anorexia. Sociol. Health Illness, v.3, n.2, p.94471, 2005.

GAVIN, J.; RODHAM, K.; POYER, H. The presentation of "Pro-anorexia" in on line group interactions. Qual. Health Res., v.3, n.18, p.325-33, 2008.

GOldenberG, M. Gênero e corpo na cultura brasileira. Psicol. Clin., v.17, n.2, p.65-80, 2005.

HALL, S. A identidade cultural na pós-modernidade. Rio de Janeiro: DP\&A, 1999.

HINE, C. Etnografia virtual. Barcelona: UOC, 2004.

KOZINETS, R. Netnography: doing ethnographic research on line. London: Sage, 2010.

LIRA, L.C. Narrativas de Ana: corpo, consumo e self em um grupo pró-anorexia na internet. 2006. Dissertação (Mestrado) - Faculdade de Ciências Sociais, Universidade Federal de Pernambuco, Recife. 2006.

MAUSS, M. As técnicas do corpo. In: São Paulo: Cosac Naify, 2003. p.399-422. (Org.). Sociologia e Antropologia.

MEDINA, C.B. Anas e Mias em blogs na internet: a exposição de si na contemporaneidade. In: CONGRESSO BRASILEIRO DE CIẾNCIAS DA COMUNICAÇÃO, 30., 2007, Santos. Anais... Santos: Intercom - Sociedade Brasileira de Estudos Interdisciplinares da Comunicação, 2007. p.1-15.

MINAYO, M.C.S. O desafio do conhecimento: pesquisa qualitativa em saúde. São Paulo: Hucitec, 2008.

MISKOLCI, R. Corpos elétricos: do assujeitamento à estética da existência. Rev. Estud. Fem., v.14, n.3, p.681-93, 2006.

NIEMEYER, F; KRUSE, L.H.M. Constituindo sujeitos anoréxicos: discursos da revista Capricho. Texto Contexto Enferm., v.17, n.3, p.457-65, 2008.

ORGANIZAÇÃO MUNDIAL DE SAÚDE. C.B.C.D. Classificação Estatística Internacional de Doenças e Problemas Relacionados à Saúde. São Paulo: Edusp, 2008.

PEREIRA, C.S. Os wannabees e suas tribos: adolescência e distinção na internet.

Rev. Estud. Fem., v.15, n.2, p.357-82, 2007.

POSSAS, C. Epidemiologia e sociedade: heterogeneidade estrutural e saúde no Brasil. São Paulo: Hucitec, 1989.

RECUERO, R. Comunidades em redes sociais na internet: um estudo de uma rede pró-ana e pró-mia. Faro, v.1, n.2, p.1-21, 2005.

REIS, V.A.; SILVEIRA JÚNIOR, P.M. Vínculos no ciberespaço: websites pró-anorexia e bulimia. In: COLÓQUIO EM COMUNICAÇÃO E SOCIABILIDADE, 1., 2008, Juiz de Fora. Anais... Juiz de Fora: UFMG, 2008. p.1- 15. 
SANTOS, L.A. Reflexões sobre a tríade corpo, comer e comida. In: (Org.).

O corpo, o comer e a comida: um estudo sobre as práticas corporais e alimentares no mundo contemporâneo. Salvador: EDUFBA, 2008. p.21-48.

SIBILIA, P. O pavor da carne: riscos da pureza e do sacrifício no corpo-imagem contemporâneo. Famecos, v.25, n.25, p.68-84, 2004.

TIERNEY, S. The dangers and draw of online communication: pro-anorexia websites and their Implications for users, practitioners, and researchers. Eat. Disord., v.14, p.181-90, 2006.

TORRI, G.; BASSANI, J.J.; VAZ, A.F. Dor e tecnificação no contemporâneo culto ao corpo. Pensar Prat., v.10, n.2, p.261-73, 2007.

RAMOS, J.S.; NETO, A.F.P.; BAGRICHEVSKY, M. Cultura de la identidad pro-anorexia: características de un estilo de vida en una comunidad virtual. Interface - Comunic., Saude, Educ., v.15, n.37, p.447-60, abr./jun. 2011.

Anorexia nerviosa es una enfermedad inscrita en la Clasificación Internacional de Enfermedades. Sin embargo, jóvenes pro-anoréxicas creen que están adoptando un "estilo de vida". El objetivo es analizar la "identidad cultural" de estas jóvenes, investigando una comunidad virtual brasileña. Metodológicamente se utilizó la etnografía virtual en tres "significados básicos" identificados en la comunidad: la tensión entre la anorexia como una enfermedad frente al estilo de vida, los ideales de perfección y el sentido de pertenencia al grupo. Los resultados sugieren que la identidad pro-anorexia se diferencia del modelo biomédico y que el cuerpo delgado sirve de referencia para el reconocimiento social y éxito económico. Foros online permiten la construcción de una identidad basada en el anonimato. Se concluye que los estudios de prácticas anoréxicas en comunidades virtuales deben ser alentados porque contribuyen con la comprensión del universo joven y colaboran con la promoción de políticas y acciones para salud de los adolescentes.

Palabras clave: Anorexia. Comportamiento de los adolescentes. Webcast. Internet. 